\title{
Analysis on House Furnishings of Ming and Qing Dynasties and Their Cultural Characteristics
}

\author{
Dejun Wei \\ Department of Design \\ Shandong College of Arts \\ Jinan, China \\ e-mail: weidejun669@sina.com
}

\begin{abstract}
The traditional Chinese house furnishing shows dignified magnanimous artistic conception which has become a great characteristic of the East. This paper paid great attention to China's house furnishings of different areas in Ming and Qing dynasties and their cultural characteristics were analyzed and summarized by three parts, namely parts of house furnishings, principles and methods of their constitution and furniture styles.
\end{abstract}

Keywords—house; furnishing; culture

\section{INTRODUCTION}

After the foundation of the Ming dynasty, the etiquette system for every stratum of society in daily life was stipulated strictly, $t$ deeply influenced houses of people from every stratum of society. The hierarchy of houses became an important part of the entire set of etiquette. The level of a house could be measured by its location, dimension, standard width of a room, roof style, color painting and decoration style. In addition, details and styles of furnishings were important means of expression.

\section{HOUSE FURNISHINGS OF MING AND QING DYNASTIES AND THEIR CULTURAL CHARACTERISTICS}

China covers a large territory and China's geographical positions and Chinese living habits are different, hence many houses with different local features were built in the Ming dynasty. Among them, houses of Huizhou and Suzhou, caves in loess areas, quadrangle courtyards in Beijing, Sichuan dwellings and Hakkas houses in Guangdong and Guangxi etc. were typical, which formed different house furnishings.

People in Huizhou paid great attention to the longitudinal axis of the center. As a result, the indoor layout of a hall that was the main site for family activities was generally symmetrical along with the longitudinal axis with a simple and proper furniture layout and a solemn and elegant style. The interior furnishing and furniture were closely related and Ming-style furniture of a simple, thick, exquisite and elegant layout was an important part of the indoor environment of Huizhou dwellings in the Ming dynasty. Original colors and textures of wood were used without any ornament for concealing which brought dark colors and firm and fine texture. The modeling of Ming-style furniture was sophisticated with a simple and vigorous image, exquisite, rigorous and precise workmanship and an elegant and refined style. It had deep breath of life and a high artistic touch. From left to right (facing the table), furnishings on the long narrow table in front of the hall is: wind, an everringing bell, Maojian and a vase. Generally, ornaments on the wall are four pictures of wind, sunshine, rain and snow on the left and four pictures of plum, orchid, bamboo and chrysanthemum on the right. And in the middle of the front, a Zhu Family Instruction or a landscape painting is hung with couplets on both sides. Sometimes, the landscape painting will be replaced by a picture with Sui (for exorcising evil spirits) or the god of longevity (indicating luck). In the bedroom, the furniture layout was usually planned to be practical and comfortable according to the master's living habits and needs. Huizhou people believed in that the left is for the senior and the right is for the young, so the senior usually used the left room and the younger generation used the right room. The bed in the bedroom was put along the beam to avoid "sleeping under the beam", indicating bad luck.

Suzhou was the economic and cultural center in regions south of the Yangtze River. People's lives were wealthy with abundant natural resources. Rich businessmen and bureaucrats always gathered here, therefore the residential scale was large too. Characteristics of Suzhou houses were summarized as follows: the first is plane and space combination of doors and courtyards and a layout feature of building by the river; the second is the yard combining natural and artistic conception together; the third is that injection and fusion of culture and art made Suzhou residential buildings become both living space and spiritual shelter. Most Suzhou houses were built in the housing block, a belt area which was perpendicular to river course and streets. In the front of each hall, there will be a courtyard. The design of a courtyard was stressed very much and there were a street and a river in front of and on the back of the house respectively was a feature of the yard. For the second characteristic, Suzhou was always a prosperous area and literati were gathered here with rich cultural accumulation and a developed yard culture. The host and guests often read books, drew pictures, recited poems, enjoyed music, played instrument and Chinese chess and guessed a riddle in the parlor and the study where a courtyard was an extension of it. 
As a result, people paid great attention on the layout of the courtyard. Rocks, waters, plants, flowers, even a kiosk and a corridor made the yard scholarly or intellectual. In a word, it mixed natural beauty and literati temperament into Suzhou' $\mathrm{s}$ residential courtyard. The courtyard became a natural extension of the hall and the hall was the artificial support of the courtyard which was full of natural factors. From the third one, the Suzhou house was a living place for people to live and be sheltered. Its physiological use function was its basis and its psychological and spiritual function was attached great importance especially. In some high-class houses, colorful cultural and artistic factor were integrated and elements such as literature, pictures, painting and calligraphy, arts and crafts were full of the house which was an important approach of space organization and scene creation and formed a rich cultural atmosphere.

The layout characteristic of Beijing quadrangle courtyards is being affected by the strong feudal patriarchal system with mature dimension and space arrangement. The house defines the internal and the external strictly, is isolated from the outside and forms a free world. Generally, the plane layout is that: the house faces south located in the middle by north with a main room as a center, an east box and a west box. A courtyard, a festoon gate and south rooms are in front of the main room in order. Behind the main room there are posterior chambers. Outer walls of the east box, the west box south rooms and posterior chambers form the outer wall of the entire quadrangle courtyard. The outer wall is closed without any window except a door in the southeast corner of the outer wall for access. The living order of the quadrangle courtyards is logical. The finest material was used for the main room and the main room has the largest space. Its position is the most honorable one and it is the room for the patriarch. Pedal sit is the main way of the daily life supplemented by the mat and kang. A hall is the indoor public space of multifunction in which family sacrifice, festivals and celebrations, visits of friends and relatives, teachings, even three meals a day and family talking happen. The layout of a hall is symmetrical along central axis. The main wall of the hall is an area to put principal facility. Using the middle space of the hall as the activity site showing features of center orientation, capaciousness, tall and huge buildings and brightness. which are not only requirements for aesthetic, but also requirements for people. Furniture in the hall mainly includes tables and chairs etc. with a stable display format. According to function requirements in different sites, there is no uniform level standard about furniture display. Objects of house furnishings are wood plaques and calligraphy and painting hung a dresser and pottery on the long narrow table indicating safety and luck. Side rooms and boxes are generally used as bedrooms which are places for rest and sleep. Its layout is characterized by silence, secret, elegance and freedom. The bed is put in a dark area of the room and is far from the door. Otherwise, curtains, screens and canopies are used to conceal.

At that time, Suzhou was the most famous place of furniture production. The shape of Suzhou's Ming dynasty furniture was graceful and simple with little gingerbread and architrave. The section of the component was tiny and most of them were round with rigor and solid mortise and tenon joint which were of harmony and unity with the modeling. Oil paint can exert the intrinsic beauty of texture and colors of wood. This Ming-style furniture was always on behalf of China's furniture until the Qianlong period in the Qing dynasty.

Compared with the Ming dynasty, house furnishings in the Qing dynasty didn't change too much. However, modeling art styles of Ming and Qing dynasties are completely different. The main characteristics can be summarized as follows: graceful and luxury with fine gingerbread, exquisite workmanship, dignified modeling and an imposing manner. Take the dignified modeling as an example, the total size of material of Qing-style furniture is bigger than that of Ming-style furniture. As a result, its local size is bigger too. For being graceful and luxury, expression ways of furniture making are complex and various, including inlay, sculpture, painting which is in stark contrast with Ming-style furniture that is simple but elegant and comfortable. Qing-style furniture has a great variety from civilian's tables and beds to royal tables, chairs, cabinets and couches, most of which are exquisitely carved and adopted smooth and fluent curve modeling with exquisite workmanship and proper decoration

.is much exposure and little concealing, a simple and elegant decorative style is formed. This transparent structure produces special senses of strength, openness and balance in the Chinese architecture generating harmonious beauty. The other level is structure such as doors, windows, shelf, partitions and partition doors, which are parts of strong decoration. Its decretive function and structure function are nearly equivalent. The other level is furniture, which is a removable and functional part. Its layout sequence is usually in line with functions and form different key points of decorative furnishings and it is an important factor of house furnishing. Contents such as structure, architecture, ornaments, furniture and furnishing generate harmonic stable three-dimensional space sequence combination with a unified style, clear layers and ordered key points.

Second, principle and method analysis of house furnishing composition: the principle of sequence composition fully embodies the unity of functions and arts, which not only satisfies the requirement of being easy to use, but also forms a balanced and stable visual effect, making users feel comfortable and joyful psychologically and physically. The architectural structure is the basis of decorative furnishings of a house. The architectural structure determined the style frame of a house, so it is the basis of decorative furnishings of a house. In different historical periods, due to differences of history, nations and development degrees of architectural technology, different layout styles of architectural structure were formed in different periods. Thus, the house furnishings shall follow these styles. Most floor plans of Chinese traditional residential courtyards are symmetrical. There must have two boxes besides the main room. Most courtyard combination is a semi enclosed three-section courtyard, quadrangle courtyard and addition of cross yards. In addition, functions 
of rooms are very clear, realizing basic requirements of furnishings. Building construction and decoration provides a style of house furnishings. The development outline of the ancient Chinese architectural art is very clear, but its course is flexural. Early building construction and function requirements only can realize the role of "a shelter from the storm". Later, with the development of production and society, "graceful buildings and high platforms" as well as exquisite decoration and miscellaneous and trivial sculpture created by hundreds of artisans appeared.

Third, pattern analysis of furniture: furniture is combination of architecture and furnishings in aspects of structure and styles. The modeling of furniture is evolved from the architectural form. Chinese traditional architecture uses wooden beams as the structural framework. Chinesestyle furniture also uses stakes and beams as its frame. The rim of a board and tension brace of backbones applies the same way as the architectural wooden structure. Modeling, flower ornaments and sculpture of Chinese-style furniture are also similar with architectural decoration. Furniture is closely related to architecture in aspects of structure and styles. From the development of architecture and furniture, we can see that laws of development of traditional furniture and traditional architecture are the same. Architecture is the exterior, while furniture is the interior. Buildings protect furniture, while furniture supplements buildings. Both of them were originated and developed from the long history and excellent cultural tradition of the Chinese nation and extract essence of socioculture, life style and customs and aesthetic taste of all ages. Thus, furniture becomes the key and the rally point of the layout in house furnishings and provides a basis and a platform for other furnishings. Furnishings provide vivid details for rooms. Based on practical furnishings, traditional house furnishings embody diversities of furnishings, rich artistry and cultural connotation fully. Though the furnishing is the last level of house decoration, it usually plays a spiritual role in house decoration, and provides vivid details and concrete contents for rooms.

\section{CONCLUSION}

The traditional Chinese house furnishing in Ming and Qing dynasties has become a great characteristic of the East. It contains two kinds of quality: one is solemn and elegant bearing and the other is dignified magnanimous artistic conception, symbolizing a profound and original spirit prospect. The Chinese style expressed dignified magnanimous artistic conception and full and magnificent colors.

\section{REFERENCES}

[1] The Chinese History of Architecture Drawing Board, the Chinese History of Architecture [M]. Beijing: China Building Industry Press, 986

[2] Wang Zhenfu. Chinese Architectural Art [M]. Taiyuan: Shanxi Education Publishing House, 2003

[3] Xu Qingwen. Introduction to the Traditional Chinese Lifestyle [M]. Jinan: Shandong Education Press, 2002
[4] Wang Xifu. Indoor Decorative Furnishings of Chinese Traditional Dwelling Houses [J]. Furniture and Environment, 2000 (02) 